\title{
Assessment of Effects of an Oil Pipeline on Caribou, Rangifer tarandus granti, Use of Riparian Habitats in Arctic Alaska, 2001-2003
}

\author{
Lynn E. Noel ${ }^{1}$, Matthew K. Butcher ${ }^{2}$, Matthew A. Cronin ${ }^{1,3}$, and Bill Streever ${ }^{4}$ \\ ${ }^{1}$ ENTRIX, Inc., 1600 A Street, Suite 304, Anchorage, Alaska 99501 USA; e-mail: 1noel@entrix.com \\ ${ }^{2}$ ENTRIX, Inc., 2701 First Avenue, Suite 500, Seattle, Washington 98121 USA \\ ${ }^{3}$ Present address: University of Alaska Fairbanks, Palmer Research Center, 533 East Fireweed Avenue, Palmer, Alaska 99645 \\ USA \\ ${ }^{4}$ BP Exploration (Alaska) Inc., 900 East Benson Boulevard, Anchorage, Alaska 99519 USA
}
Noel, Lynn E., Matthew K. Butcher, Matthew A. Cronin, and Bill Streever. 2006. Assessment of effects of an oil pipeline on Caribou, Rangifer tarandus granti, use of riparian habitats in arctic Alaska, 2001-2003. Canadian Field-Naturalist 120(3): 325-330.

Elevated oil field pipelines may alter Caribou (Rangifer tarandus granti) movements and delay or prevent access to insect relief habitat. In an attempt to determine if the $40-\mathrm{km}$ elevated Badami pipeline in northern Alaska changed Caribou use of riparian habitats at the three river crossings where the pipeline is buried, we quantified Caribou habitat use at all three crossings using time-lapse video cameras and aerial distribution surveys over three summers. We compared habitat use, behavior and duration of observations among pipeline and non-pipeline sites. We used a block experimental design with cameras at four sites at the three river crossings to evaluate differences in numbers of Caribou per day at pipeline and non-pipeline sites. At each crossing, four cameras were positioned, with one pair of cameras next to the pipeline (pipeline sites) and one pair of cameras 1.8-3.2 km upstream from the pipeline (non-pipeline sites); where cameras monitored the river bank and channel (river habitat) and the tundra within about $200 \mathrm{~m}$ of the river (tundra habitat). Peak numbers of Caribou per day occurred during early July 2003 and mid-July 2001 and 2002. Large numbers of Caribou recorded north of the pipeline during aerial surveys did not usually correspond with increased number per day recorded by cameras suggesting Caribou probably also crossed the pipeline outside of the riparian areas. We assessed local changes in riparian habitat use by comparing the numbers of Caribou per day in river and tundra habitats at pipeline and non-pipeline sites and found no difference. We assessed regional changes in riparian habitat use by comparing numbers of Caribou per day at pipeline sites and at non-pipeline sites and found no difference. Caribou groups spent an average of 1 minute longer at tundra pipeline sites and groups spent 30 seconds longer feeding and trotting at pipeline sites, but these differences were not significant.

Key Words: Caribou, Rangifer tarandus granti, aerial survey, insects, Badami pipeline riparian habitat, summer, time-lapse video, Alaska.

In northern Alaska, Caribou (Rangifer tarandus granti) regularly use insect relief habitats during the summer (Cameron and Whitten 1979; Murphy and Curatolo 1987; Walsh et al. 1992; Pollard et al. 1996a, b; Young and McCabe 1998). This frequently involves north-south movements from inland feeding habitats to coastal insect relief habitats (Cameron and Whitten 1979; Pollard et al. 1996b). Oil transport pipelines traverse open tundra and riparian corridors, often in an eastwest direction, so there is the potential for obstruction of movements to and from insect relief habitats (National Research Council 2003). Previous work has shown that pipelines associated with roads can have an impact Caribou movements (Murphy and Lawhead 2000); however, impacts from pipelines not associated with roads and elevated $\geq 1.5 \mathrm{~m}$ above the tundra, a height designed as a mitigation to allow Caribou passage (Cronin et al. 1994*), have not been documented.

One such pipeline on Alaska's north slope runs $40 \mathrm{~km}$ from the Badami oil production site to the oil fields at Prudhoe Bay. Most of the Badami pipeline is elevated about $1.5 \mathrm{~m}$ above the tundra, but it is buried under- neath the three rivers it crosses (Figure 1 and 2). Caribou are common in this area during the summer, and aerial surveys document animals on the north and south sides of the pipeline, indicating that they cross the pipeline (Jensen and Noel 2002*; Jensen et al. 2003*; Noel and Cunningham 2003*). However, the elevated sections of this pipeline could alter Caribou movement and delay access to coastal habitats (National Research Council 2003). If this occurs, Caribou should be more likely to cross the pipeline in the riparian zones (including the river and adjacent tundra) where the pipeline is buried. We recorded Caribou by using time-lapse video and aerial distribution surveys over three years to assess whether Caribou use of riparian habitats was influenced by the pipeline.

\section{Methods}

Study Area

A 40-km elevated pipeline extends from the Badami facility $\left(70^{\circ} 9^{\prime} 2.71 " \mathrm{~N}, 147^{\circ} 1^{\prime} 25.93 " \mathrm{~W}\right)$ across undeveloped terrain to the Endicott pipeline near the Prudhoe Bay oil field $\left(70^{\circ} 15^{\prime} 18.25^{\prime \prime} \mathrm{N}, 148^{\circ} 1^{\prime} 32.75^{\prime \prime} \mathrm{W}\right.$, Figure 


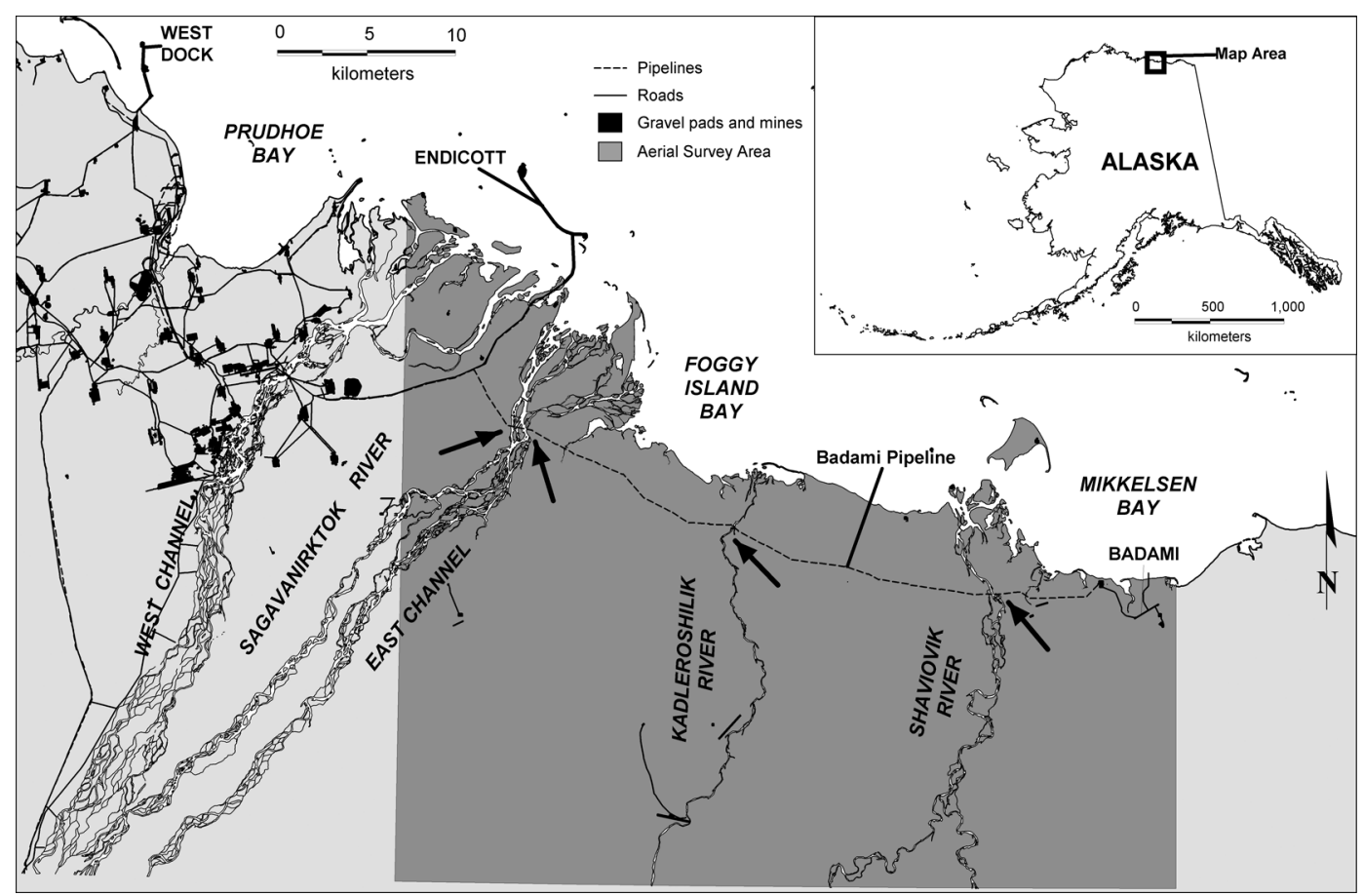

FIGURE 1. Study area, North Slope, Alaska. Arrows indicate study sites.

1). The Badami pipeline is elevated $\geq 1.5 \mathrm{~m}$ above the tundra surface for $>99 \%$ of its length. This pipeline is buried beneath the East Channel of the Sagavanirktok, Shaviovik, and Kadleroshilik rivers. At the Sagavanirktok and Shaviovik rivers, the pipeline is buried for about $1000 \mathrm{~m}$; at the Kadleroshilik River the pipeline is buried for about $400 \mathrm{~m}$. The Sagavanirktok River crossing is split into two channels by a large vegetated river bar; requiring two sites to be monitored. The tundra between these river channels is a gently rolling thaw-lake plain landscape with elevation rises of 6 to $8 \mathrm{~m}$ (Walker and Acevedo 1987).

\section{Time-Lapse Videography}

We used time-lapse video camera assemblies to monitor Caribou movements between 19 June and 26 August in 2001, 2002, and 2003. Each camera assembly consisted of a GYYR ${ }^{\mathrm{TM}}$ TLC1800-DC time-lapse videocassette recorder and a Panasonic ${ }^{\mathrm{TM}}$ WV-CL 322 color CCTV digital camera equipped with a Compu$\operatorname{tar}^{\mathrm{TM}}$ APC auto-iris $8.5 \mathrm{~mm}$ semi wide-angle lens (Pollard and Noel 1994*; Noel et al. 1998). Each assembly was powered by four 12-volt, 80 -amp sealed lead acid batteries, charged by four Solarex ${ }^{\mathrm{TM}} \mathrm{SX}-56$ photovoltaic panels. The video recorder, camera, and batteries were housed in insulated aluminum casings to protect them from weather and animals. The time-lapse video recorders were set to record at 3-4 second intervals. Markers were placed $100 \mathrm{~m}$ from each camera to assist in determining visibility and to standardize the area sampled. Cameras had a $72^{\circ}$ view angle resulting in a $7260-\mathrm{m}^{2}$ field of view out to $100 \mathrm{~m}$ (i.e., the sampling area). Videotapes were changed at 10-13 day intervals.

The cameras were arranged as follows at four river crossings (Figure 1): (1) the east side of the buried East Channel Sagavanirktok crossing (E Sag), (2) the west side of the buried East Channel Sagavanirktok crossing (W Sag), (3) the east side of the Shaviovik River crossing (Shav), and (4) the east side of the Kadleroshilik River crossing (Kad). At each crossing, four cameras were positioned, with one pair of cameras next to the pipeline (pipeline sites) and one pair of cameras 1.8-3.2 $\mathrm{km}$ upstream from the pipeline (non-pipeline sites) (Figure 2). One of each pair of cameras monitored the river bank and channel (river habitat), while the other monitored the tundra within about $200 \mathrm{~m}$ of the river (tundra habitat).

Non-pipeline sites with river channel width and configuration and tundra habitats similar to those of the corresponding pipeline sites were selected to reduce variability. This arrangement allowed us to collect Caribou data in four settings at each river crossing (Figure 2): (1) along the pipeline corridor where the pipeline was buried under the river (buried pipeline site/river habitat), (2) along the pipeline corridor where the pipeline was elevated above the tundra (elevated pipeline site/tundra habitat), (3) 1.8-3.2 km upstream from the 
pipeline at the river's edge (non-pipeline site/river habitat), and (4) upstream from the pipeline on the tundra (non-pipeline site/tundra habitat).

Videotapes were viewed and the number of Caribou groups seen each day by each of the cameras was recorded. Caribou groups were defined by lapses of 1530 seconds of tape with no Caribou observations. For each group observed within $100 \mathrm{~m}$ of the camera, data for the number of individuals, sex/age category, predominant behavior, and direction of movement were recorded. Caribou group behaviors included: feeding, resting (laying), standing, walking, trotting, running, and swimming.

\section{Aerial Surveys}

Eleven systematic aerial strip-transect surveys were completed from a Cessna 206 fixed-wing aircraft (Caughley 1977) to document the number of Caribou within a $1043 \mathrm{~km}^{2}$ area surrounding the Badami pipeline between 25 June and 1 August 2001-2003 (Figure 1) (Jensen and Noel 2002*; Jensen et al. 2003*; Noel and Cunningham 2003*). Transect centerlines were spaced at $1.6-\mathrm{km}$ intervals, oriented north-south, and centered on township and section lines from 1 : 63360 scale U.S. Geological Survey (USGS) topographic maps. Transects were flown at $90 \mathrm{~m}$ altitude and $130-180 \mathrm{~km} / \mathrm{h}$. Two observers, each searching an 800$\mathrm{m}$ wide area on their side of the transect centerline, provided $100 \%$ coverage of the survey area. Aircraft wing struts were marked to enable visual control of transect strip width and estimation of distance between Caribou groups and the survey aircraft (Pennycuick and Western 1972). Global positioning system (GPS) receivers were used for navigating the aircraft along transects and for estimating the location of the aircraft when animals were observed. The locations of animals were recorded using a GPS receiver linked to a notebook computer. For each sighting, species, group size, group composition, and perpendicular distance from the aircraft were recorded. Coordinates of animal sightings were later calculated using the visual estimates of distance from the aircraft to offset the GPS aircraft positions. Geographic Information System (GIS) software was used to complete geographic summaries.

\section{Weather Data}

An automated weather station was established near the East Channel Sagavanirktok River. Temperature (T100 probe with radiation shield) and wind (Gill 3cup anemometer, Gill low threshold vane) sensors transmitted readings at 5-min intervals to a data recorder which averaged and stored values as mean hourly wind speed and mean hourly air temperature data (Dryden $\mathrm{R} 2{ }^{\circledR}$ data logger, Anchorage, Alaska).

\section{Data Analysis}

The cameras were arranged to create a complete block experimental design (Steel and Torrie 1980). Each river location (E Sag, W Sag, Kad, or Shav) was a complete block containing all four settings: buried
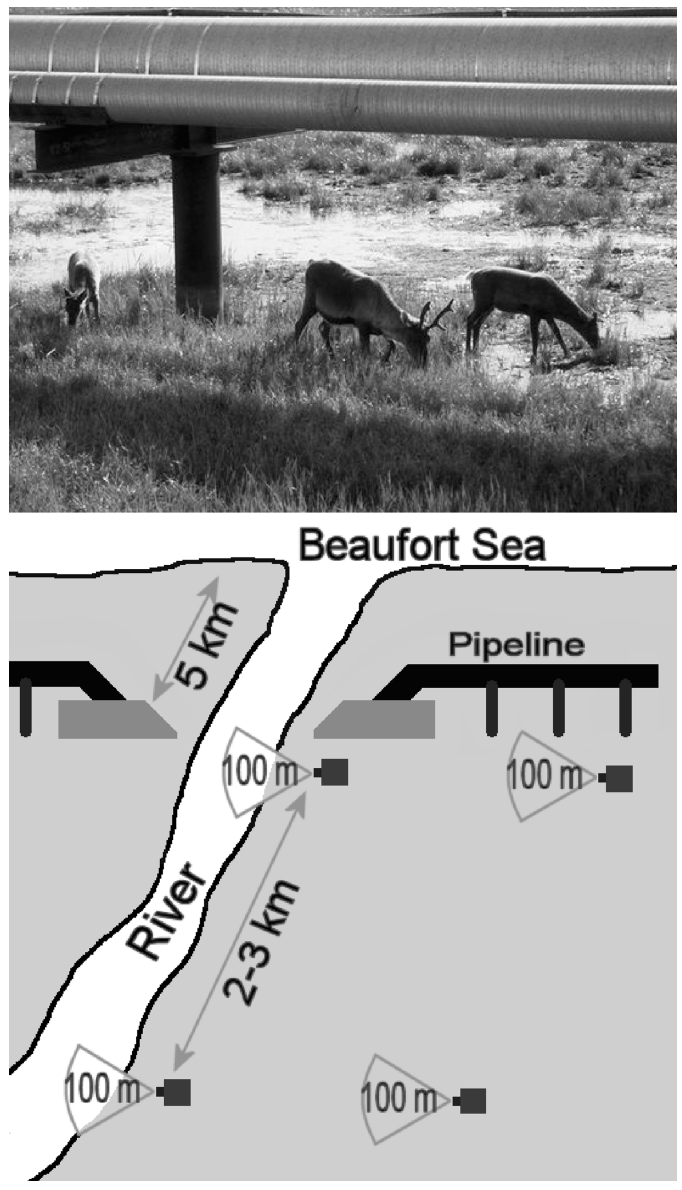

FIGURE 2. Top: An elevated pipeline on Alaska's North Slope. Bottom: Schematic showing the positions of four cameras relative to a river and the Badami Pipeline. As shown, the pipeline is buried at river crossings. (Drawing by Daniel King not to scale.)

pipeline site/river habitat, elevated pipeline site/tundra habitat, non-pipeline site/river habitat, and non-pipeline site/tundra habitat, resulting in two cameras at the pipeline site and two cameras at the non-pipeline site (Figure 2). The potential for the pipeline to change Caribou habitat use was assessed by comparing mean numbers of Caribou per day (averaged for each year) among the four settings, and by evaluating the direction, duration and behavior of Caribou observed by the time-lapse cameras. We summarize the aerial survey data to compare the numbers of Caribou recorded using time-lapse cameras to the numbers of Caribou within the survey area, north of the pipeline and within riparian habitats. Riparian habitats were defined as a $200 \mathrm{~m}$ area surrounding the Sagavanirktok, Kadleroshilik, and Shaviovik rivers (Figure 1). Observation duration, direction of movement, behavior, temperature, and 
wind speed were compared among habitats and with and without the pipeline using a general linear model and analysis of variance (ANOVA).

The block design allowed for the evaluation of local (within the riparian zone) and regional changes in Caribou use of riparian habitats. At a local scale, if Caribou changed habitat use due to the elevated pipeline within the riparian zone (i.e., within $200 \mathrm{~m}$ of the river bank), we would expect more Caribou to use river habitat at the pipeline sites compared to river habitat at the non-pipeline sites, as Caribou would avoid the elevated portion of the pipeline by crossing at the river where the pipeline was buried. At a regional scale, if Caribou moved toward the riparian corridors along the pipeline corridor, we would expect to see more Caribou at the pipeline sites (both river and tundra habitats) than at the comparable non-pipeline sites (both river and tundra habitats), as blockage of direct northsouth movements by the elevated pipeline would lead to east-west Caribou movements along its length.

We used complete block ANOVA to assess local and regional changes in Caribou use of riparian habitats. Because of the lack of independence between counts of Caribou on consecutive days, we averaged the number of Caribou per day across each year, and used this mean as the response variable, giving an overall sample size of $n=47$. The ANOVA model was:

Caribou per day $=$ Constant + Location + Year + Pipeline + Habitat + (Pipeline $\times$ Habitat $)$,

where:

Constant $=$ overall mean Caribou per day

Location $=$ a block for each river crossing $(\mathrm{W} \mathrm{Sag}, \mathrm{E}$ Sag, Kad, or Shav),

Year $=$ each year of the study $(2001,2002$, and 2003)

Pipeline $=$ pipeline site or non-pipeline site, and

Habitat $=$ river or tundra.

All statistical analyses were conducted with SYSTAT $^{\circledR}$ Version 10.2 (SYSTAT ${ }^{\circledR}$ Software Inc., Richmond, California).

\section{Results and Discussion}

Peak numbers of Caribou per day were recorded during early July in 2003 and mid July in 2001 and 2002 (Figure 3). Peaks in mean daily temperature coincided with increased numbers of Caribou per day recorded by cameras during late June and early July, but trends were not consistent. During the 11 aerial surveys between 25 June and 1 August 2001-2003, 36\% of the Caribou were distributed north of the pipeline within $13 \%$ of survey area and $17 \%$ of the Caribou were within riparian habitats representing $9 \%$ of survey area (Table 1). Generally, when few Caribou were recorded within the survey area, no Caribou were recorded by the time-lapse cameras (Table 1, Figure 3 ).

The sex-age distribution of Caribou occuring within the survey area was dominated by adult cows (61\%$70 \%$ ) based on the aerial survey data (Table 1). These sex-age distributions are estimates and likely underrepresent calves based on the results of fall composition surveys for this herd of $28 \%$ bulls, $42 \%$ cows and
30\% calves (Lenart 2003*). Sex-age distributions based on time-lapsed video were more similar to fall composition results (Lenart 2003*), but nearly half of the individuals were unclassified (Table 1).

Mean annual Caribou per day by camera ranged from 0.3-20.4 across habitats, pipeline configurations, river locations, and years (Table 2). Least squares means from the ANOVA show that Caribou were more abundant in tundra habitats (mean $=8.9$ Caribou per day) than in river habitats (mean $=3.3$ Caribou per day) (Table 3). This difference between habitats was the only significant factor $(P=0.02$, Table 4$)$.

If local habitat use changed because of the presence of the elevated pipeline, more Caribou would have been seen in river habitat than in tundra habitat at the pipeline sites. This local effect was reflected in the ANOVA Habitat $\times$ Pipeline interaction term, which was not significant $(P=0.64$, Table 4$)$. The difference between mean Caribou per day in tundra and river habitats (7.6 and 3.2 Caribou per day, respectively) was smaller for pipeline sites than for non-pipeline sites (10.4 and 3.5 Caribou per day, respectively).

Because we detected no effect on numbers of Caribou per day, we evaluated the duration that Caribou were recorded at pipeline and non-pipeline sites on the tundra (Table 5). Blockage of northward or southward movements across the pipeline corridor could result in delays at pipeline sites, which would be reflected in duration and behavior at these sites. Groups moving north appeared to spend an average of one minute longer at pipeline sites in tundra habitats, while groups moving south spent about two minutes longer at non-pipeline sites (Table 5). A general linear model was used to test whether the presence of the pipeline affected observation duration for Caribou moving northward potentially seeking refuge from insects. Neither the presence of the pipeline nor the explanatory variables habitat (river versus tundra), temperature, and wind speed (atmospheric conditions may have an effect on the severity of insect harrassment) had statistically significant $(P=0.05)$ effects on the observation duration for Caribou moving northward. Duration of group behaviors indicated that Caribou spent about $30 \mathrm{sec}-$ onds longer feeding and trotting on the tundra at pipeline sites than non-pipeline sites (Table 6). Separate ANOVAs were applied to the duration of feeding, trotting, and walking activities in different habitats (river and tundra) and in the presence or absence of the pipeline. For trotting and walking, neither habitat nor pipeline or their interaction were significant explanatory variables $(P>0.2)$. For feeding Caribou, the duration within tundra (mean $=00: 01: 09)$ was significantly longer than within river (mean $=00: 06: 35, P=0.002$ ).

If the pipeline caused regional changes in Caribou riparian habitat use, we would expect to see more Caribou at the pipeline sites than at the non-pipeline sites. However, the difference between mean Caribou per day at the pipeline and non-pipeline sites (5.4 and 6.8 Caribou per day, respectively, Table 3) was not signifi- 


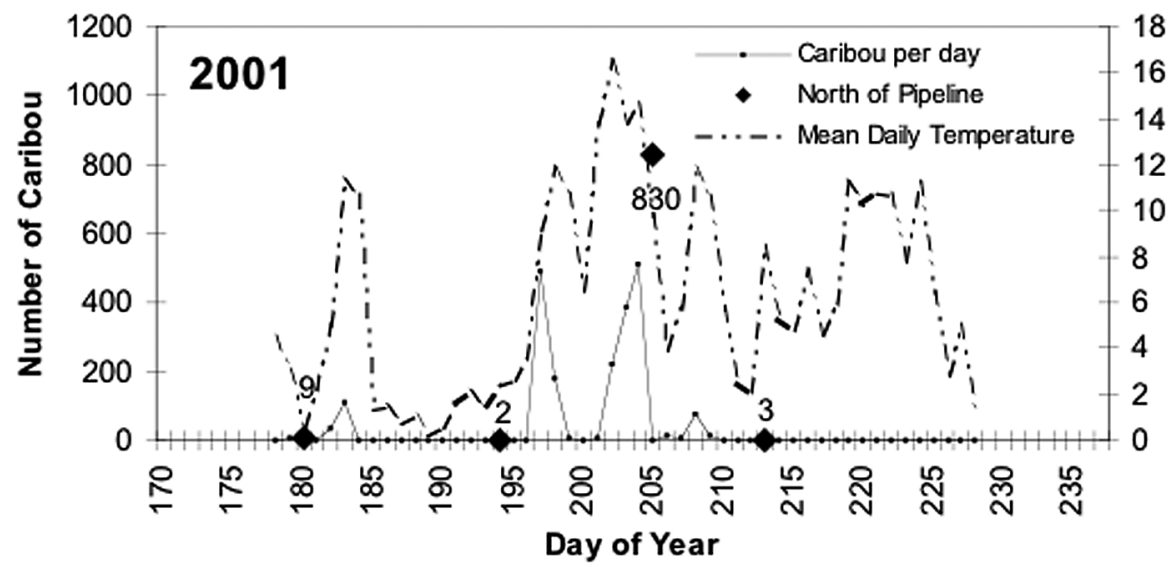

ํㅗㄴ
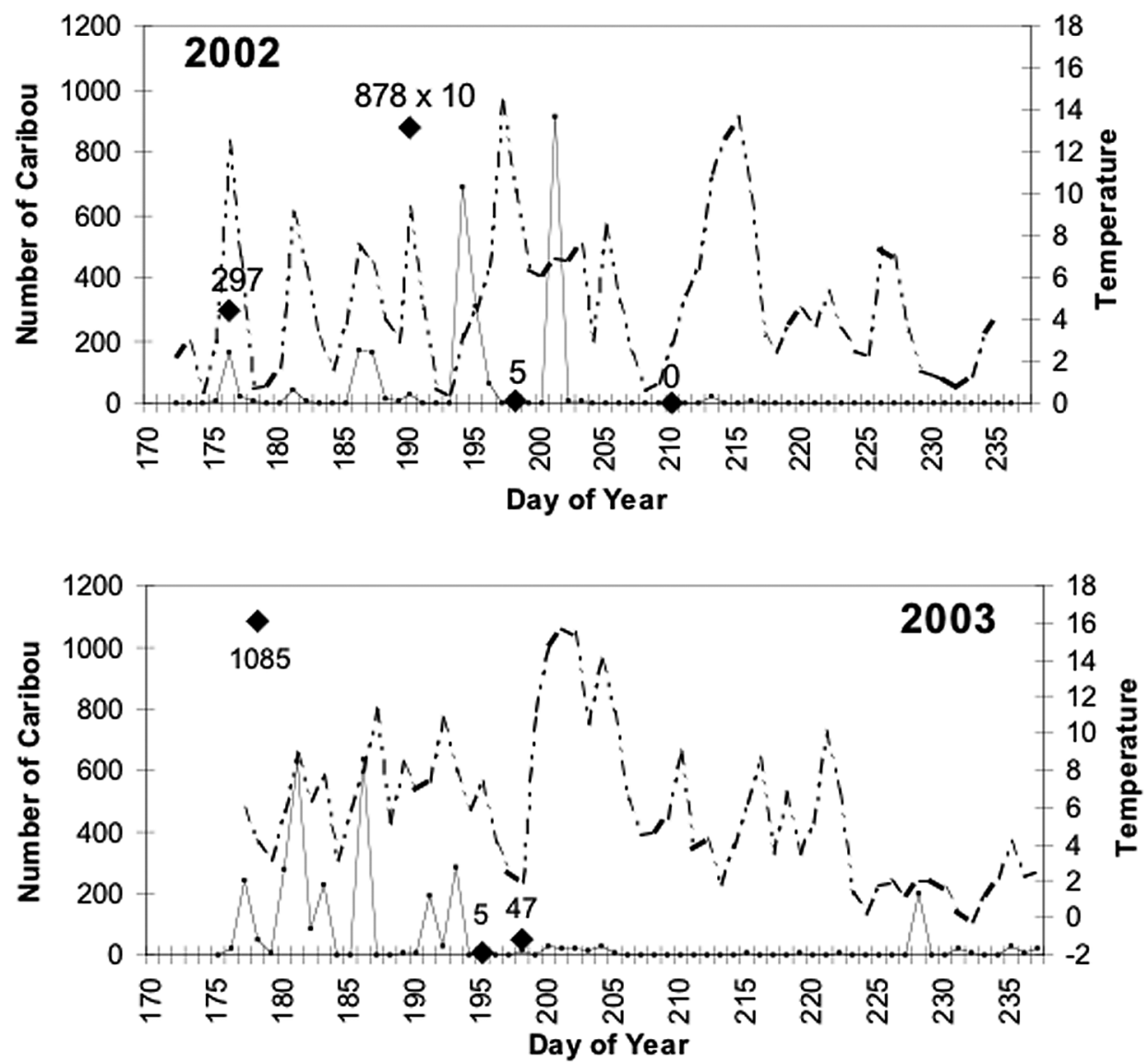

FIGURE 3. Comparison of numbers of Caribou recorded per day for all time-lapse cameras, numbers of Caribou recorded in riparian habitats north of the Badami pipeline corridor during aerial surveys (Figure 1), and mean daily temperature $\left({ }^{\circ} \mathrm{C}\right), 19$ June (day 170) 26 August (day 238) 2001-2003, North Slope, Alaska. 
TABLE 1. Summary of Caribou sex-age classes, numbers, and distribution within the aerial survey area and observed in riparian areas at pipeline and non-pipeline sites using time-lapse video 19 June-26 August 2001-2003, North Slope, Alaska. For bulls, cows, and calves $\%$ is per cent of classified. Unclassified $\%$ is per cent of total.

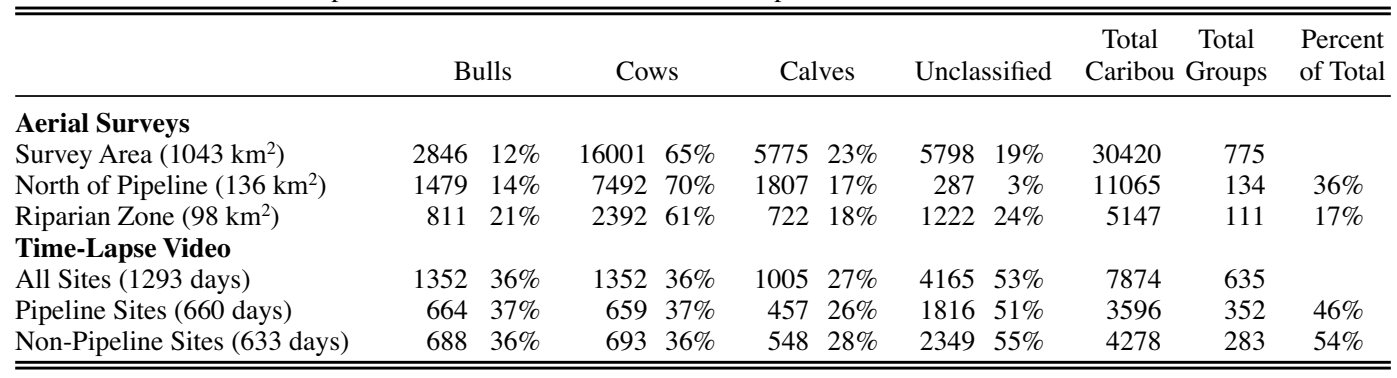

TABLE 2. Total Caribou, days of camera operation, and mean Caribou per day by camera with standard deviation (SD) for all three years pooled, 19 June-26 August 2001-2003, North Slope, Alaska.

\begin{tabular}{lllcrr}
\hline \hline Camera Site & Habitat & Pipeline & $\begin{array}{c}\text { Total } \\
\text { Caribou }\end{array}$ & $\begin{array}{c}\text { Days of camera } \\
\text { operation }\end{array}$ & $\begin{array}{c}\text { Caribou per } \\
\text { day (SD) }\end{array}$ \\
\hline W Sag 1 & Tundra & Elevated & 562 & 89.88 & $5.8(35.32)$ \\
W Sag 2 & River & Buried & 22 & 87.62 & $0.2(1.47)$ \\
W Sag 3 & Tundra & Non-pipeline & 488 & 86.88 & $5.1(25.70)$ \\
W Sag 4 & River & Non-pipeline & 8 & 88.67 & $0.1(0.82)$ \\
E Sag 1 & River & Buried & 243 & 78.60 & $2.8(14.56)$ \\
E Sag 2 & Tundra & Elevated & 1122 & 77.88 & $12.9(63.03)$ \\
E Sag 3 & River & Non-pipeline & 320 & 81.23 & $3.6(19.21)$ \\
E Sag 4 & Tundra & Non-pipeline & 596 & 77.78 & $6.7(29.63)$ \\
Kad 1 & River & Buried & 151 & 79.67 & $1.6(7.19)$ \\
Kad 2 & Tundra & Elevated & 234 & 88.42 & $6.5(13.54)$ \\
Kad 3 & River & Non-pipeline & 591 & 84.98 & $19.1(77.81)$ \\
Kad 4 & Tundra & Non-pipeline & 1222 & 59.81 & $7.1(27.53)$ \\
Shav 1 & River & Buried & 629 & 80.20 & $7.3(27.52)$ \\
Shav 2 & Tundra & Elevated & 633 & 78.00 & $2.6(14.29)$ \\
Shav 3 & River & Non-pipeline & 225 & 76.32 & $9.5(48.67)$ \\
Shav 4 & Tundra & Non-pipeline & 828 & 76.93 & 1292.87 \\
\hline Grand Total & & & 7874 & & \\
\hline \hline
\end{tabular}

TABLE 3. Caribou per day by pipeline and habitat with sites pooled (buried pipeline site/river habitat, elevated pipeline site/tundra habitat, non-pipeline site/river habitat, non-pipeline site/tundra habitat), 19 June-26 August 2001-2003, North Slope, Alaska.

\begin{tabular}{lccc}
\hline \hline & \multicolumn{2}{c}{ Habitat } & \\
\cline { 2 - 3 } Pipeline & River & Tundra & Total \\
\hline Pipeline & 3.2 & 7.6 & 5.5 \\
Non-pipeline & 3.5 & 10.4 & 6.8 \\
Total & 3.3 & 8.9 & 6.1 \\
\hline \hline
\end{tabular}

cant $(P=0.57$, Table 4$)$. Peaks in the number of Caribou north of the pipeline in 2002 and 2003 did not coincide with large numbers of Caribou recorded at cameras, suggesting that Caribou crossed the pipeline outside of riparian areas (Figure 3).

The results of this study support the conclusion that pipelines elevated $\geq 1.5 \mathrm{~m}$ above the tundra did not cause changes in Caribou riparian habitat use at buried river crossings or delay north-south movements to and from coastal insect relief habitats (Cronin et al. 1994*, Murphy and Lawhead 2000).

TABLE 4. Results of ANOVA for Caribou per day along three rivers crossed by the Badami pipeline during 19 June-26 August 2001-2003, North Slope, Alaska.

\begin{tabular}{lcrrrr}
\hline \hline Source & Sum-of-Squares & df & Mean-Square & $F$-ratio & $P$ \\
\hline Pipeline (Present, Absent) & 22.08 & 1.00 & 22.08 & 0.33 & 0.57 \\
Habitat (River, Tundra) & 415.86 & 1.00 & 415.86 & 6.29 & 0.02 \\
Location (i.e., Block) (E Sag, W Sag, Kad, Shav) & 170.90 & 3.00 & 56.97 & 0.86 & 0.47 \\
Year (2001, 2002, 2003) & 29.50 & 2.00 & 14.75 & 0.22 & 0.80 \\
Interaction (Pipeline $\times$ Habitat) & 14.40 & 1.00 & 14.40 & 0.22 & 0.64 \\
Error & 2512.10 & 38.00 & 66.11 & & \\
\hline \hline
\end{tabular}







Documents Cited [marked $*$ in text citations]

Cronin, M. A., W. B. Ballard, J. Truett, and R. Pollard. 1994. Mitigation of the effects of oil field development and transportation corridors on caribou. Final Report to the Alaska Caribou Steering Committee by LGL Alaska Research Associates, Inc., Anchorage, Alaska.

Jensen, P. G., and L. E. Noel. 2002. Caribou distribution in the range of the Central Arctic Herd. Part A: Aerial surveys in the Milne Point Unit, Prudhoe Bay Oilfield, Badami, and Bullen Point to Staines River study areas, summer 2001. Chapter 2A in Arctic Coastal Plain caribou distribution, summer 2001. Edited by M. A. Cronin. Unpublished report for BP Exploration (Alaska) Inc. by LGL Alaska Research Associates, Inc., Anchorage, Alaska. Pages 2-1-86.

Jensen, P. G., L. E. Noel, and W. B. Ballard. 2003. Caribou distribution in the Badami and Bullen Point to Staines River study areas, Alaska, summer 2002. Chapter 1 in Caribou distribution in the range of the Central Arctic Herd, summer 2002. Report for BP Exploration (Alaska) Inc. by LGL Alaska Research Associates, Inc. (LGL Report P662) 42 pages plus appendices.

Lenart, E. A. 2003. Unit 26A and B Caribou management report. Pages 304-326 in Caribou management report of survey and inventory activities 1 July 2000-30 June 2002. Edited by C. Healy. Alaska Department of Fish and Game, Juneau, Alaska.

Noel, L. E., and E. E. Cunningham. 2003. Caribou distribution in the Badami and Bullen Point to Staines River survey areas, Alaska, Summer 2003. Report for BP Exploration (Alaska) Inc. by ENTRIX, Inc., Anchorage, Alaska. 58 pages.

Pollard, R. H., and L. E. Noel. 1994. Caribou distribution and parasitic insect abundance in the Prudhoe Bay oil field, summer 1993. Report to BP Exploration (Alaska) Inc. by LGL Alaska Research Associates, Inc., Anchorage, Alaska. 70 pages.

\section{Literature Cited}

Caughley, G. 1977. Sampling in aerial survey. Journal of Wildlife Management 41: 605-615.

Cameron, R. D., and K. R. Whitten. 1979. Seasonal movements and sexual segregation of caribou determined by aerial survey. Journal of Wildlife Management 43: 626633.

Murphy, S. M., and J. A. Curatolo. 1987. Activity budgets and movement rates of caribou encountering pipelines, roads, and traffic in northern Alaska. Canadian Journal of Zoology 65: 2483-2490.

Murphy, S. M., and B. E. Lawhead. 2000. Caribou. Pages 59-84 in The Natural History of an Arctic Oil Field: Development and the Biota. Edited by J. C. Truett and S. R. Johnson. Academic Press, San Diego, California.

National Research Council. 2003. Cumulative environmental effects of oil and gas activities on Alaska's North Slope. The National Academies Press. Washington, D.C. 452 pages.

Noel, L. E., R. H. Pollard, W. B. Ballard, and M. A. Cronin. 1998. Activity and use of active gravel pads and tundra by Caribou, Rangifer tarandus granti, within the Prudhoe Bay oil field, Alaska. Canadian Field-Naturalist 112: 400-409.

Pennycuick, C. J., and D. Western. 1972. An investigation of some sources of bias in aerial transect sampling of large mammal populations. East African Wildlife Journal 10: $175-191$.

Pollard, R. H., W. B. Ballard, L. E. Noel, and M. A. Cronin. 1996a. Parasitic insect abundance and microclimate of gravel pads and tundra within the Prudhoe Bay oil field, Alaska, in relation to use by Caribou, Rangifer tarandus granti. Canadian Field-Naturalist 110: 649-658.

Pollard, R. H., W. B. Ballard, L. E. Noel, and M. A. Cronin. 1996b. Summer distribution of Caribou, Rangifer tarandus granti, in the area of the Prudhoe Bay oil field, Alaska, 1990-1994. Canadian Field-Naturalist 110: 659-674.

Steel, R. G. D., and J. H. Torrie. 1980. Principles and procedures of statistics: A biometrical approach. McGrawHill Book Company, New York. 674 pages.

Walker, D. A., and W. Acevedo. 1987. Vegetation and a Landsat-derived land cover map of the Beechey Point quadrangle, Arctic Coastal Plain, Alaska. CRREL Report 87-5. U.S. Army Corps of Engineers, Cold Regions Research and Engineering Laboratory, Hanover, New Hampshire, USA.

Walsh, N. E., S. G. Fancy, T. R. McCabe, and L. F. Pank. 1992. Habitat use by the Porcupine Caribou Herd during predicted insect harassment. Journal of Wildlife Management 56: 465-473.

Young Jr., D. D., and T. R. McCabe. 1998. Grizzly bears and calving caribou: What is the relation with river corridors? Journal of Wildlife Management 62: 255-261.

Received 17 August 2005

Accepted 19 April 2007 